The moisture is estimated first by drying it over chloride
of calcium. Sulpburic acid sbould not be used in th desicof calcium. Sulpburic acid sbould not be used in th desic-
cator, as it may spatter and cause an explosion. The explo-
sive may be extracted in a closed funnel on a dried and sive may be extracted in a closed funel on a dried and
weighed filter, or in a continuous extracting apparatus on such a filter. In the former case care must be taken that vessel and cause loss of nitroglycerine. The ethereal extrac
is put in a small weighed beaker, and evaporated on a water bath at a very gentle heat. During the evaporation at certain point the liquid gets milky as the nitroglycerine be-
gins to separate. From now on, the operation must be watched, and as soon as the turbidity vanisbes again, the The nitroglycerine still contains a little etber or acetic etherTo remove these and traces of water it is dried in an air-
pump receiver over chloride of calcium. The nitroglycerine pump receiver over chloride of calcium. The nitroglycerine two successive weighings. If it contains other substances,
like paraffine, rosin and sulpbur, which are soluble in ether they are extracted along with the nitroglycerine, but t glycerine in evaporating it, apparatus for continual extra tion are used. After the ether evaporates the residue is
dried and weiglied, then warmed with soda lye on the dried and weighed, then warmed with soda lye on the
water-bath. The rosin is dissolved and can be removed by decanting and washing with distilled water. filter, washed, dried at $100^{\circ} \mathrm{C}$., and weiglied. Then the nitroglycerine is taken up with strong alcohol, decanted, alcobol, dried, and weighed. To separate the sulphur and paraffine the mixture is warmed with an aqueous solution
of ammonium sulphide, atlowed to cool, the film of paraffine
broken tbrough, solution decanted, and dried, and weighed -the quantity of nitroglycerine and of sulphur foighe by difference. In gelatinous explosives
which contain mono or dinitro-cellulose, the extractio which contain mono or dinitro-cellulose, the extraction
with etber will go on very slowly, because the dissolving protects the rest from solution. In this case it is better to extract both cotton and nitro ylycerine at the same time witb alcohol and ether, and then precipitate the cotton witb chloroform. If camphor is also present, which can only be added to a few of the gelatinous ones, it must be extracted
witb carbon disulpbide frum the residue, freed from etber and cbloroform Camphor bas never yet been found in the and cbloroform. Campbor bas never yet been found in the
same mixture with paraffine, sulpbur, or rosin. If they
should be present all togetlier they would be extracted along with the camplor by the disulphide, and can be separated fron the others by its rolatility. In the residue, atter ex
traction with ether, or alcobol and ether, there may be trinitro-cellulose, or any one or more of the other substances
already mentioned. If the qualitative analysis showed tbat already mentioned. If the qualitative analysis showed that the residue consisted only of mineral substances, it can be weigh it and then burn it and thus ascer a little organic matter left in the residue: If there are any soluble salts in it they can be extracted with bot water after
the weight of the dry residue has been found, and by evapothe weight of the dry residue has been found, and hy evapois taken along with any extractive matter also present. If dissolved in water neutralized with nitric acid, and evapoThe carbonates are converted into nitrates, and the amount of carbonic acid calculated from the difference in weight.
If the mass is ignited, then moistened when cold with nitric If the mass is ignited, then moistened when cold with nitric
acid, and freed from the excess of acid, the salts will be converted into nitrates, but the extractive matter destroyed. If, bowever, there are chlorates present, part of the salt must be ignited to convert them into chlorides and then been estimated by precipitation with nitrate of lime. The nitric acid can be estimated in another portion of the extrac
by conversion into ammonia. After estimating the bases i a sepirate portion, the extractive can be found by differ-

The residue insoluble in water is treated as follows: If it contains trinitrocellulose, a portion is removed from the filterand boiled with quite a concentrated solution of sodium
sulpbide, which dissolves the nitrocellulose; t be rest is collected on a weighed filter, wasbed carefully with distilled water, dried, and weighed. The loss of weight gives the
proportion of nitrocellulose in the part taken, and is calcuor if there is none there, the rest is Ireated with dilute hydrochloric acid to remove any carbonate of lime or magnesia (also alumina), and these bases estimated in the sclu-
tiou. The residue is washed, dried, and weighed. This residue contains the wood, charcoal, or similar organic sub-
stances, and the insoluble mineral alisorbents. The organic constituents are removed by burning, and the insolubble
mineral matter weighed, and eventually separated and estimated in the usual way If there is me absorbent used, as wood fiber and charcoal, there is no saticfactory metbod for separating them, and we must be satisfied
with an elementary analysis, and judge of the substances by the relative proportions of carbon and bydrogen.
As a rule it is necessary to separate tbe proximate constisubstance beside nitroglycerine that would affect its tion, like Nobel's infusorial dynamite, in wbich a nitrogen determination can be made as proposed by Hempel, and a commercial valuation based on it, expressed in the calculated
quantity of trinitrine. Although there is no longer much variation in the properties of the "oll, it bas been found from the experiments made by a military commission that
even in so simple a form of dynamite as Nobel's, the explosive value does not always increase and decrease in the same
proportion as the percentage of nitroglycerine. The physi-
cal relations play a part in the simplest dynamites as well as the chemical composition. Among these are the more
less perfect alsorption of the oil by the absorbent, from the less perfect alsorption of the oil by the absorbent, from the
adbesion of the particles together, on the elasticity of the preparation (in those containing gelatine), and on other simi-
lar circumstances. A nitroglycerine explosive of correct theoretical composition will he more or less completely used
up by detonation, and its true effect more or less perfectly up by detonation, and its true effect more or less perfectly condition. Indeed, under cerlain circumstances a dynamite
that is poor in nitroglycerine will produce more effect in that is poor in nitroglycerine will produce more effect in
the same medium than a fatter one having otherwise the dynamite in this respect, and thereby establisb its commer suitable means of ascertaining, by direct experiments on small scale, the explosive value of the preparation in practiHempel's metbod of estimating nitroglycerine, above re-
Hed to consists in shaking a mixture of ferred to, consists in shaking a mixture of dynamite and
sulphuric acid with mercury and measuring the volume of nitric oxide evolved. If nitrates, carbonates, and nitro. cellulose are present, the separation of nitroglycerine may
first be made by the process above described so as to avoid APPARATUS FOR THE ESTIMATION OF SULPHUR IN SPENT OXIDE.

By H. Leicester Greville, F. I.C., F.C.S.

I HAVE lately been using for estimating the sulphur in spent oxide an apparatus which I have found very con-
venient. It is sbown in the annexed illustration, and a deusing it, may possibly be of interest to some of the readers Referring to the diagram, B is a Boxetb's fat extraction 10 oz. flask, F, and at its upper extremity to the con-
1 ube, fitted by coutchouc stoppers at its lower extemity to enser, A, by means of a bent glass tube, with flexible rubG is a small circular tin vessel provided with an annular of the flask, F, rests. In using the apparatus, the cbarge of oxide, which may be from 100 to 200 grains, is placed in the
tube, $\mathrm{C}$, whicb is simply a sbort piece of ordinary test-tube, the bottom of which is contracted witlout bcing sealed. To charge this tube, the bottom is loosely plugged with tow
the weigbed quantity of oxide then introduced, followed by a further plug of tow, leaving a small space unfilled at the top of the tube. The tube with its cbarge of oxide is then
placed in the Hoxeth's tube, $B$, and four or five ounces carbon disulpbide poured in. The liquid will flow into the
flask, F, by the sipbon, D. The caoutchouc stopper of the flask, F, by the sipbon, D. The caoutchouc stopper of the
Hoxeth tube, B, is then inserted (connection being thus made to the condenser), and the apparatus is ready for use.
On sending a current of steam from a flask of boiling water, or from some other source, into the tin vessel; $G$, the carbon disulphide soon boils, and the vapor passes up the condensed liquid runs back, falling in drops into and filtering through the oxide in C. After a short time the tube,
$B$, becomes filled up to the level of the top of the sipbon, $\mathrm{B}$, becomes filled up to the level of the top of the sipbon,
D, which then starts into action the solution of sulphur

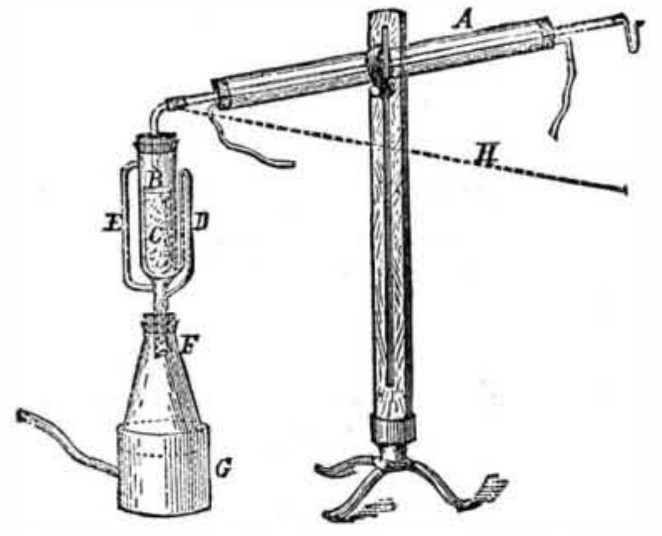

tion of filling and discharging continues automatically until oxide to the carbon disulpbide in the flask, F. The fact of
of the extraction being complete may be known by the liquid By lowering the condenser, A, into the position shown by the dotted line, $H$, the carbon disulphide may now be dis-
tilled off, leaving the sulphur in the flask, $F$, in the solid
state. the final drying being accomplisbed in a current of state; the final drying being accomplisbed in a current of
warm air or in the air batb. If the weigbt of the flask, $F$, is known, the increase in weight af ter the completion of the experiment gives the amount of sulpbur. The small bent
tube at the end of the condenser is for the purpose of preventing the escape of the heavy carbon disulpbide vapor
during distillation, at the same time that the liquid has a The great converience of this apparatus lies in its requir-
free ing so little attention. The extraction of the sulphur takes place completely and automatically, and the operator is en-
abled to devote himself to other work while the sulphur estimation is progressing.-The Journal of Gas Lighting. ASBESTOS.

AsBestos is a mineral baving a texture more or less filamentous, and by trituration is reducible to a somewhat ties.

mineral is greenish white, passing into leek green; or silver white, yellowish wbite, ocher yellow, pale flesh red, and, rate rarely, light blue. It is found sometimes in small sepa-
rates, but more usually in irregular fibrous masses. Its luster is glimmering or slightly shining, and is eitber
weak, pearly, or silky. It is easily divisible into long slenweak, pearly, or silky. It is easily divisible into long slen-
der flexible fibers, may be scratclied by the nail, and has a soft somewhat greasy feel. It is generally opque, but is
sometimes translucid on the edges. Its specitic gravity is
subject to great variety that of the most flexible and per-
fectly fibus is only 0.908 . ectly fibrous is only 0.908 ; that of the most compact is 2.313
According to an analysis of this mineral by Clenevix, it ppears to contain: 25 magnesia; 59 silex; 3 alumina; $9 \cdot 2$ Before the blowpipe amianthus melts with some difficulty
Bef and $2 \cdot 25$ oxde of iron. into an opaque glohule, which becomes dark colored by the
continued action of the flame. If exposed to a high heat in continued action of the flame. If exposed to a high heat in
an earthen crucible, it melts into a dense slag, strongly adhering to the vessel and of a yellowish gray color; the sur-
face of this slag is overspread with crystalline needles, cross. ing each otber in all directions, or radiating from a common
center. If the beat is considerably increased, the whole melts into a green glass and in a short time passes tbrough
the crucible. A specimen of aniantbus from Greenland e crucible. A specimen of aniantbus from Greenland to the full beat of a porcelain furnace, fused into a finely with grains of iron.

This mineral is met witb in potstone or serpentine rocks and crevices, unmixed with any other substance. The most beautifu comes from the Tarentaise in Savoy; it is in white
flexible filaments, somelimes a foot long, of a pure silk luster. In some parts of Corsica it is so common as to have been used by Dolomieu instead of hay or moss, to pack up Crete; Zoblitz in Saxony; Stuart wick in Sweden; Cornwall and Anglesea in England, and Portsoy in Scotland, also
furnish considerable quantities. A compact kind, wbich decomposes by exposure to the air into remarkably flexible threads, is found in the Ural mountains in Siberia. Amianthus is also found in great abundance in a few localities in
the United States. The fibrous texture of amianthus, its incombustibility, and
the little alteration that it undergoes even in a strong beat, were early noticed, especially among the Eastern nations; and methods were found out of drawing the fibers into
tlread and afterward weaving it into cloth. Tbis, when by throwing it into a bright fire; the stains were burnt out,
bere and the cloth was then removed, but little altered in its
properties, and of a dazzling white. In the rich and luxu-
rious times of the Roman Empire this incombustible cloth was purcliased at an enormous price for the purpose of
wrapping up the bodies of the dead previous to their being wrapping up the bodies of the dead previous to their being
laid in the funeral pile. The practice of burning the dead falling into disuse, occasioned the manufacture of amian-
thine cloth to be neglected, and at length entirely forgotten in Europe; but though it ceased to be an article of luxury or necessity, yet the method of its preparation attracted the notice of travelers and occupicd the time of the curious.
Ciampini, of Rome, in 1691 gave the following method of preparing incombustible cloth: Having previously steeped
the amiantbus in warm water, divide its fibers by gently all the extraneous matter; then pour on repeatedly very hot atter as long as it continues to be in the least discolored. wothing will be now left but the long fibers, which are to
be carefully dried in the sun. The bundles of thread are to be carded with very fine cards, and the lang filaments thus ible. A small quantity of cotton or wool is to be mixed, and lhread, taking care that in every part the amianthus may be
the principal material. The clnth being then woven in the usual manner, is to be plared in a clear charcoal fire to burn
off the cotton and oil, wben the wbole remaining tissue will be pure white amianthus. The sborter fibers that are incapa-
ble of being woven, have been sometimes made into paper, mon paper, except that a greater proportion of paste or size is required. After laving lieen made red hot, however, this paper becomes bibulous and brittle. Amianthus threads are
also sometimes used as perpetual wicks for lamps; they also sometimes used as perpetual wicks for lamps; they require, however, to be cleaned occasionally from the soot
that collects about them, and the fibers in the hottest part of the flame are apt to run together, so as to prevent the due ployed in the manufacture of pottery; being reduced to fine filaments, it is kneaded up with the clay, and the vessels which are made of this mixture are lighter, less brittle, and
more capable of bearing sudden alteralious of heat and cold than common pottery. Many patents bave been taken ou some of the most important of wbich are as follows: lining for safes; lamp wicks; fire brick and crucibles; packing for engines of various kinds; boiler covering; for porcelain manu-
facture, of teetb especially, placed on tbe side of the muffle to isolate the biscuit from the slide aud prevent its becoming attached thereto in the process of baking; as an anti friction
composition for journals, etc. ; for moulded articles; for roofing and flcoring cement; for refrigerators; ink; paper 2. Common Asbestos.-The color of this mineral is leek or
- The

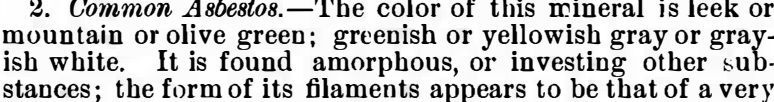
stances; the form of its filaments appears to be that of a very long rbomboidal prism; it is shining or glimmering, with
somewhat of a greasy luster; its fracture is fibrous and much striated. It flies, when broken, into long splintery frag ments; it is translucid at the edges and may be scratched by
the nail witb some difficulty, Specific gravity $2 \cdot 5$ to $2 \cdot x$. Wiegleb gives the component parts of common asbestos as
48.45 magnesia, 46.66 silex, and 4.79 oxide of iron. This mineral is of more frequent occurrence than amiantbus,
being found almost universally accompanying serpentine insensible gradations into the preceding species. 3. Ligmiform Asbestos - Tbe color of this mineral is yellow or Isabella brown. It is found massive and is internally
glimmering. Its fracture is thin and finely foliated; it is opaque, may be scratched by the nail, adberes to the tongue,
and bas a meager feel. Its specific gravity is $2 \cdot 051$. It is infusible per se before the blowpipe. It is met with princi-
pally in the Schneeberg of Tyrol in the sane gangue witb galena, blende, commcn asbestos, strablstein, and gypsum.
4. Mountain Cork or Mountain Leather. The color of this mineral is yellowish or reddisb wbite, yellowish green, or
ocher yellow. It is found amorphous in thick or thin plates; it is weakly glimmering internally. It bas a thick, uneven,
somewhat foliated fracture; is opaque, somewhat elastic,
and floats upon water. The specific gravity is 0.68 to 0.99 . Bergman gives the following analysis of its composition: $26 \cdot 10$ magnesia, $56 \cdot 2$ silex, 2 alumin
of iron.-Pottery and Glassioare Rep.

\section{LIQUEFACTION OF OZONE}

Le Génie Civil gives an account of a successful attempt at the liquefaction of ozone wbich was recently made
by Messrs. Hautefeuille and Cbappuis. It is only by Messrs. Hautefeuille and Cbappuis. It is only
recently that oxygen bas been liquetied, and bitherto its
strange allotropic form bas resisted all efforts to cbange it from its gaseous condition. By subjecting a mix ture of
ozone and oxygen to a pressure of one bundred and twentyfive atmospheres, or nineteen hundred pounds to the square and fifty degrees below zero of Fabrenbeit's scale, these deep indigo-blue color, which, although oltained under
such enormous tension, proved to bave a certain amount of stability, and evaporated only slowly when the pressure was reduced one-balf. Even under the ordinary pressure of the air some drops of the blackish liquid lingered for a few movapor, which on returning to its ordinary
to have undergone no cliemical change. 